\title{
Ging-Hsi Wong and Chinese physiopsychology
}

\author{
Shu Zheng \\ Institute for the History of Natural Science, Chinese Academy of Sciences, Beijing 100190, China
}

Ging-Hsi Wong (1897-1968) was a Chinese psychologist, an academician of the prestigious Academia Sinica (The Academia Sinica was founded in Mainland China in 1928 by the Kuomintang Nationalist Government. It was reestablished in Taipei after the Chinese Civil War), and a professor in several universities in China and the United States. As one of the pioneers of Western psychology in the country, he played an important role in establishing the fields of Physiopsychology and Neuroscience in China.

Wong's interest in Psychology, however, did not start from the beginning of his scholarship. In fact, he graduated from the Economics Department of Peking University in 1919. As a young student who passionately supported the New Culture Movement in China, Wong pioneered the use of modern vernacular Chinese and was regarded as "very promising" by renowned Chinese litterateur Lu Xun. The turning point of his career came in 1920, when he was sent by Peking University to Johns Hopkins University in the US to study with the psychiatrist Adolf Meyer. Since then, he began his illustrious career in the fields of Physiopsychology and Neuroscience. He eventually received his Ph.D. from Johns Hopkins in 1923.

After his graduation, Wong spent most of his time in China from 1924 to 1948. By successively holding leadership roles in different universities and institutes, he made enormous contributions to the education and institutionalization of Physiopsychology in China. In 1924, Wong became the dean of

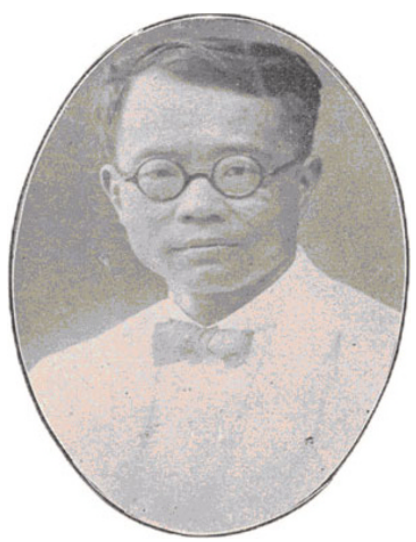

Ging-Hsi Wong

the Education Department of Zhongzhou University in Henan Province. In 1927, he worked hard to establish the Psychology Department and the Psychology Institute of Sun Yat-sen University in Guangdong Province and was subsequently appointed as the director of both organizations. There, he also established the first laboratory of neurophysiology in China. The Psychology Department of Peking University invited Wong to be part of the faculty in 1930 , and eventually appointed him to be the dean. During his tenure, he also established the first psychology laboratory in Peking University. In 1934, Wong became the director of the Institute of Psychology of the Academia Sinica, and in this capacity, he was able to establish new laboratories in Shanghai and Nanjing. In 1948, the Academia Sinica officially appointed Wong as an academician.

Wong emphasized the importance of education in the development of psy- chology. In his article entitled, "The Most Important Consideration for Promoting Science-Developing Talents," (Wong, 1932) he regarded cultivating research talents as the most important element in ensuring the development of science, even much more important than developing the research environment itself. (Yang, 1991)

With this spirit, Wong strived to offer his students the most comprehensive and appropriate learning experience. According to the historical materials of Sun Yat-sen University, Wong's course designs not only focused on the wide range of concrete modern psychological knowledge but also emphasized the history of psychology and English study. He also occasionally gave public speeches to promote public interest in psychology. His efforts paid off, and he had cultivated some of the most outstanding psychologists and neurologists in China. Hsiang-Tung Chang (19072007), a world-renowned Chinese neurophysiologist and an academician of the Chinese Academy of Sciences, recalled that Wong "pointed out the path leading to the world of neuroscience.... At his suggestion and encouragement..., this experience proved to be decisive in shaping my way of thinking in my later scientific career" (Squire, 2001).

Apart from teaching, Wong achieved widely recognized scientific accomplishments, some of which he obtained under rough experimental conditions during his stay in China. For example, he was the first to introduce an electronic instrument to the research of 


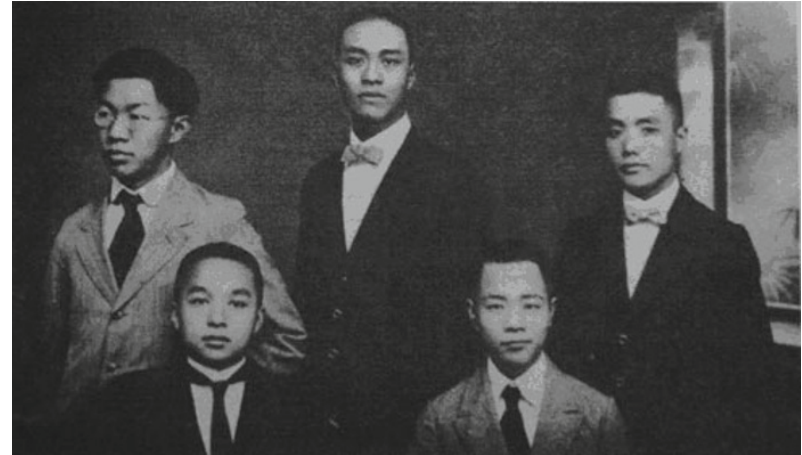

Ging-Hsi Wong (first row, first right) in 1920

brain functions in China. He was among the first to study skin potential reflex and pointed out that the reflex was due to the secretion of sweat glands and not consciousness. He also discovered the relationship between the activity of a female rat and its oestrous cycle, using a revolutionary research method in the study of mammalian behavior. In addition, Wong was not just the first scientist to describe the action potentials in the superior colliculus produced by the light stimulation of the retina, he was also the first to study cortical regions responding to the contraction and dilation of the pupil. Professor Hsiang-Tung Chang's description, to a certain extent, accurately portrays Professor Wong, "a good teacher and scientist with a remarkable acumen in research and deep understanding about the nature of science education". Indeed, without the foundation he laid, the development of the fields of Physiopsychology and Neuroscience in China would have been considerably slower.

\section{REFERENCES}

Huang, Y. (1999). History of Sun Yat-sen University (1924-1949), Guangzhou: Sun Yat-sen University Press. (黄义祥. (1999). 中山大学史稿 (1924-1949). 广
州: 中山大学出版社 .)

Lu, X. (1935). The corpus of the modern literature of china-the second volume of fiction compiler shanghai. Shanghai Liangyou Press. (鲁迅 . (1935). 《中国新文 学大系. 小说二集》导言. 上海: 上海良 友图书公司.)

Lu, Z. (2001). The story of Wong GingHsi. Neurosci Bulletin 17, 357. (鲁子惠. (2001). 汪敬熙先生传略. 中国神经科学 杂志 $17,357$.

Shepherd, G. (2009). Creating modern neuroscience: the revolutionary 1950s. London: Oxford University. pp. 109.

Squire, L.R. (2001). The history of neuroscience in autobiography. Vol 3, San Diego. U.S.A: Academic Press California. pp. 146.

Vision, D.T.W. (1988). Vision: Structure and Function. Hartwell Street: World Scientific Publishing Co. Pte. Ltd. pp. 3-6.

Wong, G.-H. (1932). The most important consideration for promoting sciencedeveloping talents, Independent Critic 26 , 10-14. (汪敬熙. (1932). 提倡科学研究最 应注意的一件事一人才的培养. 独立 评论 26,10-14.)

Yang, T. (1991). Patronage of sciences: the China foundation for the promotion of education and culture. Special Issue of Academia Sinica Institute of Modern History 65 (杨翠华. (1991). 中基会对科学的 赞助. 中研院近代史研究所专刊 65.) 